\title{
A REVIEW ON PROMISING ANTIBIOTIC THERAPY BY NOVEL DELIVERY SYSTEMS
}

\author{
PRIYANKA R*, SAYANI BHATTACHARYYA
}

Department of Pharmaceutics, Krupanidhi College of Pharmacy, Bengaluru - 560 035, Karnataka, India.

Email: priyankareddy192@gmail.com

Received: 30 November 2017, Revised and Accepted: 20 January 2017

ABSTRACT

The introduction of a new moiety of drugs for antibiotics in the market is getting declined. Antibiotic resistance is a major threat to human health worldwide. Many life-saving antibiotic drugs are rendered ineffective. Resistant bacterial infections are difficult to treat because of the poor response to antibiotics. Hence, utilizing the novel methods/approaches for the development of formulation into its novel delivery can prevent bacterial resistance. This review article explores the various promising approaches for delivery of antibiotics in the form of liposomes, solid lipid nanoparticles, microspheres, dendrimers, inhaled antibiotics, and polymeric particles. These approaches of delivery have been proven to provide innovative and novel delivery of antibiotic by enhancing the therapeutic effectiveness, targeting at the site of action, enhanced activity, and penetrability at intracellular pathogens, thereby reducing side effects, toxicity, and the chances of bacterial resistance.

Keywords: Antibiotics, Liposomes, Solid lipid nanoparticles, Polymeric particles, Microspheres, Dendrimers, Inhaled antibiotics.

(c) 2018 The Authors. Published by Innovare Academic Sciences Pvt Ltd. This is an open access article under the CC BY license (http://creativecommons. org/licenses/by/4. 0/) DOI: http://dx.doi.org/10.22159/ajpcr.2018.v11i5.23999

\section{INTRODUCTION}

Infectious diseases continue to be one of the main reasons for mortality and morbidity [1]. Introduction of antibiotics in the medical field has made significant gains in the health status and enabled the development of modern medical procedures [2]. Antibiotics play an important role in ensuring safe surgical procedures, organ transplants, chemotherapy, and a great weapon against many infections such as plague, tuberculosis (TB), and pneumonia [2,3]

Antibiotic resistance is a global public health threat. Overconsumption and unnecessary use of antibiotics increased the rate of antibiotic resistance around the world. The use of antibiotics generates resistance to their effect, by decreasing their effectiveness in the prevention and cure of disease [4]. Modes of action and resistance mechanism of some antibiotics are given in Table 1. Among the resistance pathogens, methicillin-resistant Staphylococcus aureus (MRSA), vancomycinresistant enterococcus, vancomycin-resistant $S$. aureus, and penicillinresistant Streptococcus pneumonia have become major clinical threats [5].

According to a report released by the World Health Organization on $30^{\text {th }}$ April - 2014, antibiotic resistance globally reveals that this serious threat is no longer be regarded as an issue for the future but rather a current crisis that requires urgent interventions [7]. To overcome the antibiotic resistance, new antibiotics are being investigated, but the US Food and Drug Administration (FDA) reported that there is a gradual decline in the introduction of new antibiotic drugs. During the period of 2008-2012, the US FDA approved only two systemic antibacterial agents for use in humans while 16 drugs approved from 1983 to 1987 [5]

The development of novel and effective strategies for enhancing the drug therapy with current antibiotics is major focus areas of research priority [5]. Novel drug delivery system has some benefit in the delivery of antibiotics. The pharmaceuticals are averse to investing novel drug delivery strategy for efficient delivery of antibiotics. The novel drug delivery methods such as self-emulsifying drug delivery system, microspheres, inhaled antibiotics, liposomes, solid lipid nanoparticles, polymeric particles, dendrimers, nanoemulsions, and nanosuspension could be promising drug delivery systems for antibiotics $[5,8]$.

\section{NOVEL DRUG DELIVERY METHODS}

Liposomes as delivery systems for antibiotics

Liposomes are concentric, bilayered vesicles in which an aqueous volume is entirely enclosed by a membranous lipid bilayer mainly composed of natural or synthetic phospholipids. Liposomes are in the size range of $0.01-5.0 \mu \mathrm{m}$ in diameter and can act as a carrier for a variety of drugs $[9,10]$. The antibacterial activity and the pharmacokinetics properties of antibiotics can be enhanced by entrapping an antibiotic in liposomes. Lipid vesicles are used as drug carriers which have influence on drug distribution and reduction of toxic effects. Some antibiotics have limited application due to toxicity and weak biodistribution because of low penetrability, so the pharmacokinetic and pharmacodynamic properties can be modified by encapsulating a drug in lipid vesicles [11]. Improved pharmacokinetic and biodistribution, target selectivity, enhanced activity against intracellular pathogens, protection of antibiotic drugs against hydrolytic activity of enzymes, decreased toxicity, enhanced penetrability, and thereby increased residence time of the drug in macrophages are the main advantages of liposomes [12].

Improved pharmacokinetic and biodistribution and decreased toxicity

Drugencapsulation in liposomal vesicles improves the pharmacokinetics and also protects antibiotics against the hydrolytic activity of enzymes and chemical and immunological deactivation. The liposomes which are given by intravenous administration are determined as foreign antigens by the immunological system and are opsonized. This causes the activation of non-specific defense mechanisms and the liposomes are taken up by the mononuclear phagocyte system (MPS), and this leads to lower blood clearance; this phenomenon is essential for intracellular pathogen eradiation [12].

\section{Enhanced activity against intracellular pathogens}

For eradicating the intracellular pathogen, the liposomal drug delivery system is effective. For treating the diseases which is caused byintracellular bacteria, rigid conventional liposomal vesicles and polyethylene glycol (PEG) coated have been referred to improved drug retention in proper tissues, provided sustained release, and decreased toxicity [12].

An overview of various reported liposomal systems with the rationale for formulation development is provided in Table 2. Filipin is the first 
antibiotic drug reported for liposomes in antibiotic drug delivery. Filipin is the polyene macrolide antibiotic, and it was reported that the hemolytic activity of filipin complex could be removed more effectively by liposomes [16]. Another research goal by Gregoriadis has been to overcome the failure of penicillin to penetrate cells of the reticuloendothelial system. He entrapped potassium benzylpenicillin in liposomes composed of egg lecithin, cholesterol, phosphatidic acid, and dipalmitoyl lecithin. These in vivo studies with rats showed lysosomal localization of penicillin-entrapped liposomes into the liver and spleen [19].

The cationic or anionic liposomes can be prepared using cationic or anionic ingredients in the liposomal formulations. The two antibiotics ciprofloxacin and vancomycin were encapsulated alone and in combination with liposomes to achieve a new antibiotic therapeutic approach against chronic staphylococcal osteomyelitis infections presenting in rabbits. Among all these formulations, enhanced antibacterial activity against $S$. aureus was observed for cationic liposomal formulation [20].

Surface modification of liposomes is another active area for delivery of antibiotics. It was reported that liposomes encapsulation of vancomycin offers increased pharmacokinetic and pharmacodynamic activity and decreased toxicity. When compared to the standard vancomycin formulation, the surface PEGylated liposomes deliver the drug more essentially to pathogens by depositing a higher concentration of drug into lung tissue. Liposome encapsulation decreases the drug distribution into the kidney and increases the drug accumulation in the lungs, liver, and spleen [21].

\section{SOLID LIPID NANOPARTICLES}

Solid lipid nanoparticles are the most effective lipid-based colloidal carriers, introduced in the early 1990s. SLNs are one of the novel potential colloidal carrier systems as alternative materials to polymers which are identical to oil in water emulsion. SLNs are in the submicron size range of 50-1000 nm and are composed of physiologically tolerated lipid components which are in the solid state at room temperature [22]. Highpressure homogenization, microemulsion technique, ultrasonication, solvent emulsification, spray drying, and double emulsion are the most commonly used technique for the preparation of SLN [23]. Many solid lipids such as stearic acid, glyceryl monostearate, glyceryl distearate, and decanoic acid have been used in preparing SLN. Various surfactants such as soy lecithin, egg lecithin, sodium cholate, sodium glycocholate, tween 20 and 80, and polaxamer 188, 182, and 407 are reported [24]. Proposed advantages of SLN include possibility of controlled drug release, high drug payload, excellent bioavailability, avoiding the use of organic solvent, no biotoxicity of the carrier, easy to scale up and sterilize, increased drug stability, and incorporation of lipophilic and hydrophilic drugs $[25,26]$. SLNs have some drawbacks such as particle growth, unpredictable gelation tendency, and unexpected dynamics of polymeric transitions [24]. Examples of solid lipid nanoparticles investigated for antibiotic delivery are mentioned in Table 3.

Oral delivery of drugs is the most preferred route for drug administration. Tobramycin is an orally administered antibiotic drug, used against seudomonas aeruginosa infections in cystic fibrosis (CF). Tobramycin has a poor absorption by intestinal cells because of active exploration of the drug through p-glycoproteins (p-gp) an ATP-dependent drug efflux pumps. Tobramycin-loaded SLNs can significantly suppress the p-gp efflux pump by penetrating the intestinal linings through endocytosis instead of passive diffusion. Tobramycin-loaded SLNs show increased pharmacokinetic activity, enhanced drug distribution in the lungs, and less drug payload to kidney [33]. A research group developed the solid lipid nanoparticles of enrofloxacin for sustained release of drug. The study showed that only $18 \%$ of drug released within $2 \mathrm{~h}$, followed by sustained release over $96 \mathrm{~h}$ [34]. This study showed that solid lipid nanoparticles are promising delivery for the sustained and prolonged release of drugs.

Table 1: Modes of action and resistance mechanisms of some antibiotics [6]

\begin{tabular}{lll}
\hline Antibiotic & Target & Mode of action \\
\hline Penicillin, Cephalosporins & Peptidoglycan biosynthesis & Hydrolysis, efflux, altered target \\
Gentamycin, Streptomycin & Translation & Phosphorylation, acetylation, nucleotidylation, efflux \\
Azithromycin, Erythromycin & Translation & Hydrolysis, glycosylation, phosphorylation, efflux, altered \\
& & target \\
Chloramphenicol & Translation & Acetylation, efflux, altered target \\
Ciprofloxacin & DNA replication & Acetylation, efflux, altered target \\
Trimethoprim, Sulfamethoxazole & C1 metabolism & Efflux and altered target \\
Rifampin & Transcription & ADP-ribosylation, efflux, altered target \\
Daptomycin & Cell membrane & Altered target \\
Colistin & Cell membrane & Altered target \\
\hline
\end{tabular}

Table 2: Overview of antibiotic liposomal development

\begin{tabular}{|c|c|c|c|c|}
\hline Lipids used for liposomal preparation & Active Ingredient & $\begin{array}{l}\text { Targeted } \\
\text { Microorganism }\end{array}$ & Rationale for Formulation & Reference \\
\hline $\begin{array}{l}\text { 1,2-dimyristoyl-Sn-glycero-3phosphocholine } \\
\text { and cholesterol }\end{array}$ & Gentamicin & P. aeruginosa & $\begin{array}{l}\text { Improvement of killing time and } \\
\text { prolongation of antimicrobial } \\
\text { activity }\end{array}$ & Ref [13] \\
\hline $\begin{array}{l}\text { Phosphatidylcholine, cholesterol, and } \\
\text { phosphatidylserine }\end{array}$ & Penicillin-G & L. monocytogenes & Treatment of intracellular infections & Ref [14] \\
\hline Egg PC, diacetyl phosphate, cholesterol & Vancomycin and teicoplanin & MRSA & Treatment of intracellular MRSA & Ref [15] \\
\hline Soybean PC, cholesterol & Ampicillin & M. luteus & $\begin{array}{l}\text { Improvement of drug stability and } \\
\text { retention of antibacterial activity }\end{array}$ & Ref [17] \\
\hline PC, cholesterol, and phosphatidylserine & Cephalothin & S. typhimurium & $\begin{array}{l}\text { Intracellular killing of the } \\
\text { microorganisms }\end{array}$ & Ref [18] \\
\hline
\end{tabular}

P. aeruginosa: Pseudomonas aeruginosa, L. monocytogenes: Listeria monocytogenes, MRSA: Methicillin resistant Staphylococcus aureus, L. monocytogenes: Listeria monocytogenes, M. luteus: Micrococcus luteus, S. typhimurium: Salmonella typhimurium 
In addition to oral delivery of solid lipid nanoparticles, they are ideal for topical application because of their prolonged residence time on the stratum corneum and their occlusive property can induce film formation on the skin [35]. Vijayan et al. developed a SLN-based drug delivery system for neem oil to treat acne and pimples. Decrease in particle size and high entrapment efficiency showed that SLNs have an ability to incorporate a high quantity of neem oil. Their results revealed that SLNs of neem oil provide a sustained effect which satisfactorily produced the antibacterial action on acne microbes [36]. A research group prepared solid lipid nanoparticles containing curcuminoids for the development of topical delivery. The formulation containing SLNcurcuminoids showed good spreadability and stability. As a result of slow release, nano-encapsulated curcuminoids showed no permeation or penetration when assayed using pig ear skin during $18 \mathrm{~h}$. The study concluded that the topical formulation is stable and can be used for the treatment of inflammatory reactions such as radiodermits [37].

Another research area for SLNs is pulmonary delivery of antibiotics. Pulmonary delivery of antibiotics through SLN is used to treat TB, a lung infection caused by bacteria, Mycobacterium TB. The antitubercular drug such as rifampicin, isoniazid, and pyrazinamide when incorporated into SLNs showed increased bioavailability. Solid lipid nanoparticles of these drugs offer drug delivery to the lungs and lymphatic system [38].

\section{POLYMERIC PARTICLES}

Polymeric particles made up of natural and synthetic polymers show high stability in vitro and in vivo, good biocompatibility, and multifunctionality. The antibiotics in polymeric particles allow slow, sustained release of drug and improve antibacterial efficacy against biofilm-related infectious disease [39]. The commonly used natural polymers are human or bovine serum albumin, gelatin, collagen, alginate, chitosan, and starch. Synthetic polymers such as poly (a-hydroxy acids), polyanhydrides, polylactide, poly lactide-co-glycolide (PLGA), and poly (fatty acid dimer-sebacic acid) are reported [40]. Encapsulated polymeric particles of antibiotics offer advantages such as improved pharmacokinetic and biodistribution and enhanced antibiotic penetration into bacterial biofilm. It also helps to overcome tissue and cellular barriers by effective targeting or responding to bacterial infected microenvironment [39].

\section{Improved pharmacokinetics and biodistribution of antibiotics}

Several problems such as poor absorption on oral administration and drug aggregation after intravenous administration can be overcomed by delivery of antibiotic as polymeric particles. An antibiotic encapsulated in polymeric particles alters the tissue distribution and plasma pharmacokinetic of the drug and increases the concentration of antibiotics at the site of infection, thus enhancing drug bioavailability [39]. After intravenous administration, the polymeric particles interact with blood cell constituents that are captured by macrophages of the MPS, and this is rapidly cleared from the blood [41]. PLGA polymer used in the polymeric particles could successfully deliver drugs to MPS tissue for the treatment of infectious disease caused by intracellular pathogens in the liver and spleen [40].
An example of polymeric particle system used for antibiotic therapy

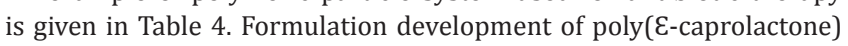
nanospheres containing amphotericin B coated with non-ionic surfactant polaxamer 188 exhibits greater therapeutic efficacy against Leishmania donovani when compared to the free drug [50]. PLGA acid considered as one of the most widely used polymers for antibiotic delivery. Formulation development of ciprofloxacin hydrochloride PLGA PNPs were prepared by W/O/W emulsification solvent evaporation method using a factorial design to study different parameters on particle size, zeta potential, and drug entrapment efficiencies. Their results revealed that there was a decrease in particle size and increase in drug entrapment efficiencies and the antibacterial activity of polymeric particles was found to be comparable to free drugs against $P$. aeruginosa and $S$. aureus [51]. However, $100 \%$ of the drug was not released after $24 \mathrm{~h}$, so these researches recognized that PLGA being negative might have low interactions with the anionic mucus of ocular infections. Then, they extended the study and incorporated cationic polymers into this PLGA formulation. In this study, they investigated the effect of positively charged polymers, namely, Eudragit ${ }^{\circledR}$ RS 100 and RL100 on physical properties, release profile, and antibacterial activity. They concluded that the PNPs are active against $P$. aeruginosa as well as against $S$. aureus to a lesser extent. Eudragit ${ }^{\circledR}$ RL containing particles were more active against microorganisms than Eudragit ${ }^{\circledR}$ RS [52]. A further paper by the same researchers has been developed to examine whether the cationic Eudragit ${ }^{\circledR}$ containing poly(lactide-coglycoside) nanoparticles can adhere to P. aeruginosa and S. aureus. Flow cytometric measurements were performed to examine the adhesion of particles to microorganisms. Their results showed that Eudragit NPs showed more bacterial adhesion with test organisms when compared with PLGA-NPs [53]. This becomes a new research area for the delivery of antibiotics based on surface charge difference between bacteria and PNP formulation. In another study, azithromycin- and rifampicin-loaded PLGA nanoparticles have been prepared, and this showed an enhance in the delivery of azithromycin and rifampicin to intracellular chlamydial infections which is caused by Chlamydia trachomatis and chlamydia pneumoniae [54]. Drug entrapment efficiency and drug encapsulation can be enhanced using different polymer ratio. It was reported that a combination of PLC and PLGA in a ratio of 80:20 improved the entrapment efficiency by $32 \%$ as compared to PLC and PLGA ratio of 60:40 [49]. Ungaro et al. formulated a PLGA nanoparticle for pulmonary delivery of tobramycin; they mentioned the importance of hydrophilic polymers such as chitosan, alginate, and polyvinyl alcohol for attaining optimal drug entrapment and release profiles [55].

Intracellular bacterial infections are very difficult to treat because of poor penetration of antibiotic drug and due to its lesser bioavailability. A research group developed biocompatible, nano-sized tetracycline encapsulated 0-carboxymethyl chitosan PNPs using ionic crossgelation technique to eradicate intracellular $S$. aureus infection. There were six-fold increases in antibacterial activity over that of the free tetracycline against intracellular $S$. aureus [56]. For targeted delivery of lectin-conjugated gliadin binding to carbohydrate receptors on Helicobacter pylori, cell wall shows the inhibitory effect with two-fold

Table 3: Overview of antibiotic solid lipid nanoparticle development

\begin{tabular}{|c|c|c|c|c|}
\hline Formulation & Drug & Targeted microorganism & Activity & References \\
\hline Compritol 888® ATO & Vancomycin & S. aureus, MRSA & $\begin{array}{l}\text { Enhanced encapsulation efficiency } \\
\text { and antibacterial activity }\end{array}$ & Ref [27] \\
\hline Stearic acid, sodium taurocholate & Tobramycin & Pseudomonas aeruginosa & Increased tobramycin bioavailability & $\operatorname{Ref}[28]$ \\
\hline $\begin{array}{l}\text { Stearic acid, phosphatidylcholine, and } \\
\text { sodium taurocholate }\end{array}$ & $\begin{array}{l}\text { Ciprofloxacin } \\
\text { hydrochloride }\end{array}$ & $\begin{array}{l}\text { Gram-positive and } \\
\text { Gram-negative bacteria }\end{array}$ & Prolonged drug release & $\operatorname{Ref}[29]$ \\
\hline Tetradecanoic acid & Enrofloxacin & S. aureus & $\begin{array}{l}\text { Sustained drug release and } \\
\text { enhanced antibacterial activity }\end{array}$ & $\operatorname{Ref}[30]$ \\
\hline Stearic acid & Norfloxacin & E. coli & Enhanced antibacterial activity & $\operatorname{Ref}[31]$ \\
\hline Hydrogenated castor oil & Tilmicosin & S. aureus & $\begin{array}{l}\text { Sustained drug release, enhanced } \\
\text { antibacterial activity }\end{array}$ & $\operatorname{Ref}[32]$ \\
\hline
\end{tabular}

P. aeruginosa: Pseudomonas aeruginosa, MRSA: Methicillin-resistant staphylococcus aureus, E. coli: Escherichia coli 
higher than gliadin nanoparticles [57]. The synthesis of $\mathrm{pH}$-sensitive nanoparticles for the delivery of antibiotics through ring-opening metathesis copolymerization has been developed by Pichavant et al. A pH-sensitive $\alpha$-norbornenyl-poly(ethylene oxide) macromer was used for the synthesis of polymeric derivatives. The drug gentamicin was linked through $\mathrm{pH}$-sensitive imine bond to a polymer, and polymeric nanoparticles were found to be non-cytotoxic when performed neutral red and (3-(4,5-dimethylthiazol-2-yl)-2,5-diphenyl tetrazolium bromide) assays. The performance of MIC measurements on Staphylococcus epidermidis at different $\mathrm{pH}$ values revealed that there was no significant inhibition of growth at $\mathrm{pH} 7$, whereas a decrease in conditions of $\mathrm{pH} 4$ and 5 was observed [58].

\section{DENDRIMERS}

Dendrimers are hyperbranched polymers with precise nanoarchitecture and low polydispersity, which are synthesized in a layer-by-layer fashion around a core unit, resulting in a high-level control of size, branching points, and surface functionality. The highly dense surface of functional groups allows the synthesis of dendrimers with specific and high binding affinities to a wide variety of viral and bacterial receptors. Polyamide dendrimers (PAMAM) are the first and most popularly studied dendrimers. PAMAM is non-immunogenic and biocompatible compounds and water soluble. PAMAM are regarded as carriers or drugs such as antibacterial and antifungal which have a capacity to improve their solubility, drug permeation, and therapeutic efficiency [59]. Based on the types of linkages and chemical moieties present, dendrimers are classified into four types: Glycol dendrimers [60], peptide dendrimers [61], janus dendrimers [62], and metallodendrimers [63].

Dendrimers are synthesized either by convergent or divergent method. In the divergent method, dendrimers grow from a multifunctional core molecule to the outward through a repetition of coupling and activation steps. The core molecules react with monomer molecule to give first-generation dendrimers. Then, the periphery of the molecules reacts with additional monomers to give several generations. Divergent method is ideal for the large-scale production of dendrimers. Side reactions and incomplete functionalization can occur when the number of generation increases. The purification of the final product is difficult in case of divergent approach. In contrast, the convergent approach is synthesized stepwise, from the periphery and progressing inward. This approach begins with coupling end groups to each branch of the monomer and followed by the activation of single functional group. The dendrons, growing branched polymeric arms are large particles; they are attached to a multifunctional core molecule. Dendrimers thus synthesized by this method can be easily purified [64]. Dendrimers with their role in antibiotic drug delivery are provided in Table 5.

Targeted intracellular drug delivery is a main research area for dendrimeric nanostructures. It was studied that Erythromycin, a macrolide antibiotic when conjugated with PAMAM dendrimers $(\mathrm{GH}-$ $\mathrm{OH}$ - link $\mathrm{NH} 2$ ) resulted in sustained release of the drug [71]. A research group synthesized conjugate of azithromycin with G4 PAMAM conjugate shows a sustained release of drug over $16 \mathrm{~h}$ and approximately $90 \%$ of the drug was released from the formulation and azithromycin readily entered the chlamydia-infected HEp-2 cells and inclusion. This study concluded that the dendrimers can efficiently deliver drugs to growing intracellular $C$. trachomatis even if the organism is in the persistent form [67]. Sulfamethoxazole PAMAM dendrimers with ethylenediamine core have been prepared to enhance its solubility, in vitro drug release, and antibacterial activity. The results revealed that when compared to water solubility of drug, it showed increased in solubility by 40 folds in $\mathrm{G}_{3}$ PAMAM dendrimers solution, and the dendrimer drug was more potent against E.coli [70].

\section{MICROSPHERES}

Microspheres are small spherical particles with diameter of $1 \mu \mathrm{m}$ to $1000 \mu \mathrm{m}$ and are free-flowing powders consisting of proteins or synthetic polymer. Microspheres are monolithic sphere or therapeutic agent distributed throughout the matrix either as a molecular dispersion of particles [72]. The prime advantages of microsphere include controlled and prolonged therapeutic activity with reduction in dosing frequency. The drug encapsulated matrix system thus helps in enhancing the solubility of poorly soluble drug, with reduction in toxicity and irritant effects in the GIT. This encapsulation provides protection of drug from enzymatic and photolytic cleavage also [73]. Less reproducibility, difference in release rate from one to another, and low drug loading for controlled release parenteral are the main disadvantages of microspheres.

Tetracycline-loaded chitosan microspheres were prepared to develop a stomach-specific drug delivery system to increase the efficacy of tetracycline antibiotic against $H$. pylori. Ionic cross-linking and precipitation technique have been established for preparing tetracycline microspheres. The aim of this study was to increase the local concentration of tetracycline in the stomach so as to eradicate $H$. pylori infection. This study concluded that tetracycline was stable in acidic medium for about $12 \mathrm{~h}$ and the entire drug content was released in the acidic $\mathrm{pH}$. The results from this study suggest the use of chitosan microspheres for the encapsulation of antibiotic drugs and may be effective against $\mathrm{H}$. pylori when it is administered locally in the stomach [74]. Cefixime-loaded microspheres showed sustained release of drug, high loading yield, and increased encapsulation efficiency [75].

Microspheres containing antibiotics have been investigated for their bactericidal activity with tetracycline-loaded chitosan microsphere against Pseudomonas aeruginosa biofilms. The result shows $60 \%$ of drug release in the first $6 \mathrm{~h}$ and continued for $24 \mathrm{~h}$. The researchers concluded that the use of tetracycline chitosan microspheres may be a new strategy for the development of drug delivery system to increase the efficacy of tetracycline against biofilm-associated $P$. aeruginosa infections [76].

\section{INHALED ANTIBIOTICS}

Inhaled antibiotics are the valuable tool in treating diseases such as $\mathrm{CF}, \mathrm{TB}$, non-CFB (non-CFB), and pneumonia. Compared to orally and parenterally given drugs, an inhaled drug dose goes directly to the targeted area. Inhalation therapy of antibiotic results in less systemic adverse effect compared to other routes of delivery. An inhaled antibiotic provides higher local drug concentration because the administered dose directly reaches the respiratory tract. There is a growing interest in the inhaled route for administration of drug [77]. A research group conducted a meta-analysis of randomized trials to study the efficacy and safety in patients with non-CF B. According to Cochrane airways group register of trials from inspection to March 2014, 12 trials with 1264 patients and eight trials on 590 patient's data have registered. Drugs like ciprofloxacin, gentamycin, aztreonam, amikacin, colistin and tobramycin were used for 4 weeks to 12 months. After the survey, they reported that the inhaled antibiotics may provide an effective therapy with stable non-CF B and chronic bronchial infection [78].

Nanosystems such as liposomes, solid lipid nanoparticles, and polymeric nanoparticles are commonly used for preparing inhalable carrier systems for pulmonary drug delivery. Other carrier systems such as magnetic nanoparticles, gold nanoparticles, nanocrtystals, and effervescent nanoparticles are currently in research to study the effect of antibiotics on delivery. Polymeric nanoparticles are widely used because they possess properties such as carrier suitability with the drugs, tissue or cell targeting, protection from therapeutic degradation, sustained release mechanism, aerosol transformability, less toxicity, and stability during aerosolization [79].

\section{Marketed formulation}

Many of the novel-based formulation are in clinical use, and some of them are in pipeline.

Some of the marketed formulations of antibiotics through novel delivery approaches are provided in Table 6. 
Table 4: Overview of antibiotic polymeric particle development

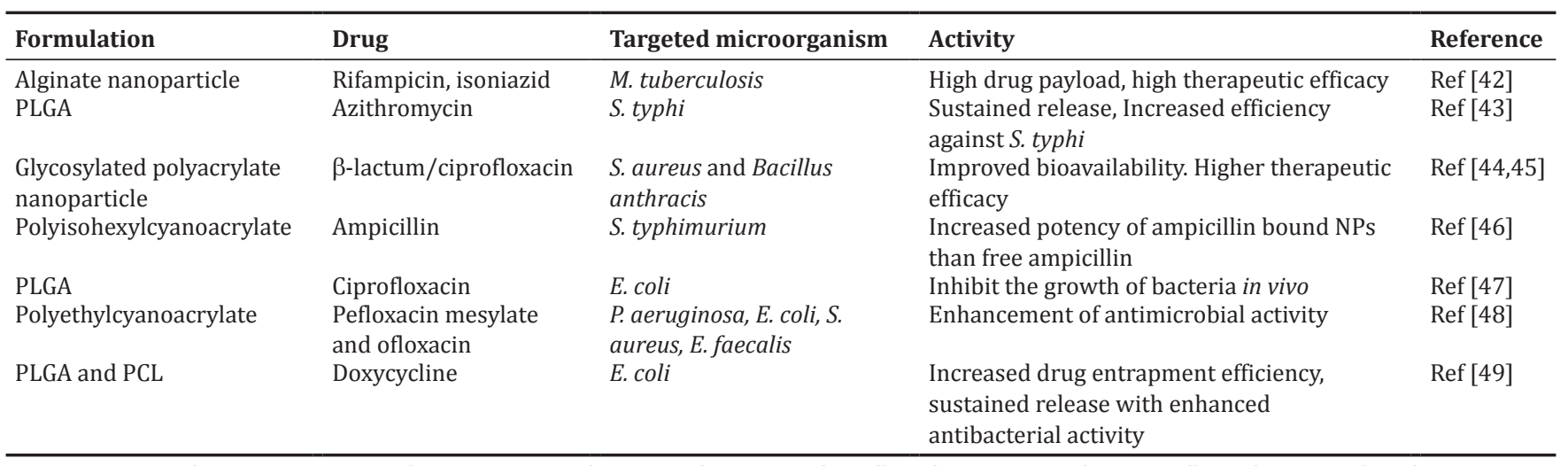

P. aeruginosa: Pseudomonas aeruginosa, M. luteus: Micrococcus luteus, S. typhimurium: Salmonella typhimurium, B. anthracis: Bacillus anthracis, M. tuberculosis: Mycobacterium tuberculosis, E. coli: Escherichia coli, PLGA: Poly lactide-co-glycolide, PCL: Poly(E-caprolactone)

Table 5: Dendrimers for antibacterial drug delivery

\begin{tabular}{|c|c|c|c|}
\hline Drug & Dendrimer & Role of dendrimer & Reference \\
\hline Silver sulfadiazine & PAMAM & $\begin{array}{l}\text { Solubility enhancer forming a nanoparticle system with enhanced } \\
\text { antimicrobial properties for the topical treatment of burn-wound infections. }\end{array}$ & $\operatorname{Ref}[65]$ \\
\hline Erythromycin and tobramycin & PAMAM & $\begin{array}{l}\text { To investigate the effect of dendrimers on antibacterial activity of two drugs } \\
\text { with different solubility profile }\end{array}$ & $\operatorname{Ref}[66]$ \\
\hline Azithromycin & PAMAM & $\begin{array}{l}\text { Conjugation with a drug to act as a carrier for efficient intracellular delivery to } \\
\text { address chlamydia infections }\end{array}$ & $\operatorname{Ref}[67]$ \\
\hline Nadifloxacin and prulifloxacin & PAMAM & Drug carrier to enhance solubility without affecting antibacterial activity & $\operatorname{Ref}[68]$ \\
\hline Triclosan & PPO-PAMAM & $\begin{array}{l}\text { Micellar carrier with high drug loading and controlled release for hydrophobic } \\
\text { drug. }\end{array}$ & $\operatorname{Ref}[69]$ \\
\hline Sulfamethoxazole & PAMAM & $\begin{array}{l}\text { Solubility enhancer to obtain increased antimicrobial activity with sustained } \\
\text { release }\end{array}$ & $\operatorname{Ref}[70]$ \\
\hline
\end{tabular}

\section{CONCLUSION}

Most of the antibacterial drugs are very difficult to administer because of their cytotoxicity to health issues, poor water solubility, and bacterial resistance. Novel drug delivery systems such as liposomes, inhaled antibiotics, solid lipid nanoparticles, polymeric particles, microspheres, and dendrimers are able to overcome these issues and provide drug delivery to bacterial infection sites. The ability of the novel drug delivery system is to enhance solubility, stability, drug entrapment efficiency, targeted drug release, and sustained release and to overcome antibiotic resistance.

\section{CONFLICT OF INTEREST}

The authors confirm that this article content has no conflict of interest.

\section{ACKNOWLEDGMENT}

The authors thank the management and Principal of Krupanidhi College of Pharmacy, Bengaluru, for providing all necessary support and facility to complete this work. We sincerely express our respect to Dr. Bharani S Sogali for her support.

\section{REFERENCES}

1. Beyth N, Houri-Haddad Y, Domb A, Khan W, Hazan R. Alternative antimicrobial approach: Nano-antimicrobial materials. Evid Based Complement Alternat Med 2015;2015:246012.

2. Abed N, Couvreur P. Nanocarriers for antibiotics: A promising solution to treat intracellular bacterial infections. Int $\mathrm{J}$ Antimicrob Agents 2014;43:485-96

3. Jamil B, Syed MA. Antibiotics: Past, present and future. J Biomol Res Ther 2016;5:2

4. Crouch E, Dickes L, Kahle A. Review on antibiotic resistance. Adv Pharmacoepidemiol Drug Saf 2015;4:1-3.
5. Kalhapure RS, Suleman N, Mocktar C, Seedat N, Govender T. Nanoengineered drug delivery systems for enhancing antibiotic therapy. J Pharm Sci 2015;104:872-905.

6. Davies J, Davies D. Origins and evolution of antibiotic resistance. Microbiol Mol Biol Rev 2010;74:417-33.

7. News Release. WHO's First Global Report on Antibiotic Resistance Reveals Serious, Worldwide Threat to Public Health; 2014. Available from: http://www.who.int/mediacentre/news/releases/2014/amr-report/en.

8. Smith AW. Biofilms and antibiotic therapy: Is there a role for combating bacterial resistance by the use of novel drug delivery systems? Adv Drug Deliv Rev 2005;57:1539-50.

9. Deshmukh RR, Gawale SV, Bhagwat MK, Ahire PA, Derle ND. A review on: Liposomes. World J Pharm Pharm Sci 2016;5:506-17.

10. Kalepu S, Sunilkumar KT, Betha S, Mohavarma M. Liposomal drug delivery system-A comprehensive review. Int J Drug Del Res 2013;5:62-75

11. Sharma A, Kumar Arya D, Dua M, Chhatwal GS, Johri AK. Nanotechnology for targeted drug delivery to combat antibiotic resistance. Expert Opin Drug Deliv 2012;9:1325-32.

12. Drulis-Kawa $Z$, Jach AD. Liposomes as delivery system for antibiotics. Int J Pharm 2009;387:187-98.

13. Rukholm G, Mugabe C, Azghani AO, Omri A. Antibacterial activity of liposomal gentamicin against pseudomonas aeruginosa: A time-kill study. Int J Antimicrob Agents 2006;27:247-52.

14. Ito M, Ishida E, Tanabe F, Mori N, Shigeta S. Inhibitory effect of liposome-encapsulated penicillin $\mathrm{G}$ on growth of listeria monocytogenes in mouse macrophages. Tohoku J Exp Med 1986;150:281-6.

15. Onyeji $\mathrm{CO}$, Nightingale $\mathrm{CH}$, Marangos MN. Enhanced killing of methicillin-resistant Staphylococcus aureus in human macrophages by liposome-entrapped vancomycin and teicoplanin. Infection 1994;22:338-42.

16. Sessa G, Weissmann G. Effects of four components of the polyene antibiotic, filipin, on phospholipid spherules (liposomes) and erythrocytes. J Biol Chem 1968;243:4364-71

17. Schumacher I, Margalit R. Liposome-encapsulated ampicillin: Physicochemical and antibacterial properties. J Pharm Sci 
1997;86:635-41.

18. Desiderio JV, Campbell SG. Intraphagocytic killing of Salmonella typhimurium by liposome-encapsulated cephalothin. J Infect Dis 1983;148:563-70.

19. Gregoriadis G. Drug entrapment in liposomes. FEBS Lett 1973;36:292-6.

20. Kadry AA, Al-Suwayeh SA, Adel RA, Allah A, Bayomi MA. Treatment of experimental osteomyelitis by liposomal antibiotics. J Antimicrob Chemother 2005;54:1103-8.

21. Muppidi K, Wang J, Betageri G, Pumerantz AS. PEGylated liposome encapsulation increases the lung tissue concentration of vancomycin. Antimicrob Agents Chemother 2011;55:4537-42.

22. Kheradmandnia S, Vasheghani-Farahani E, Nosrati M, Atyabi F. Preparation and characterization of ketoprofen-loaded solid lipid nanoparticles made from beeswax and carnauba wax. Nanomedicine 2010;6:753-9.

23. Mukherjee S, Ray S, Thakur RS. Solid lipid nanoparticles: A modern formulation approach in drug delivery system. Indian J Pharm Sci 2009;71:349-58.

24. Yadav N, Khatak S, Sara UV. Solid lipid nanoparticles-a review. Int J Appl Pharm 2013;5:8-18.

25. Mehnert W, Mader K. Solid lipid nanoparticles-production, characterization and applications. Adv Drug Deliv Rev 2012;64:83-101.

26. Muhlen AZ, Schwarz C, Mehnert W. Solid lipid nanoparticles (SLN) for controlles drug delivery-drug release and release mechanism. Eur J Pharm Biopharm 1998;45:149-55.

27. Kalhapure RS, Mocktar C, Sikwal DR, Sonawane SJ, Kathiravan MK, Skelton A, et al. Ion pairing with linoleic acid simultaneously enhances encapsulation efficiency and antibacterial activity of vancomycin in solid lipid nanoparticles. Colloids Surf B Biointerfaces 2014;117:303-11.

28. Cavalli R, Gasco MR, Chetoni P, Burgalassi S, Saettone MF. Solid lipid nanoparticles $(\mathrm{SLN})$ as ocular delivery system for tobramycin. Int $\mathrm{J}$ Pharm 2002;238:241-5.

29. Jain D, Banerjee R. Comparision of ciprofloxacin hydrochloride protein, lipid and chitosan nanoparticles for drug delivery. J Biomed Mater Res B 2008;86:105-12.

30. Xie S, Zhu L, Domg Z, Wang X, Wang Y, Li X, et al. Preparation, characterization and pharmacokinetics of enrofloxacin-loaded solid lipid nanparticles: Influence of fatty acids. Colloids Surf B 2011;83:382-7.

31. Wang Y, Zhu L, Dong Z, Xie S, Chen X, Lu M, et al. Preparation and stability study of norfloxacin-loaded solid lipid nanoparticle suspensions. Colloids Surf B Biointerfaces 2012;98:105-11.

32. Wang XF, Zhang SL, Zhu LY, Xie SY, Dong Z, Wang Y, et al. Enhancement of antibacterial activity of tilmicosin against Staphylococcus aureus by solid lipid nanoparticles in vitro and in vivo. Vet J 2012;191:115-20.

33. Gilligan PH. Microbiology of airway disease in patients with cystic fibrosis. Clin Microb Rev 1991;4:35-51.

34. Kumar SP, Arivuchelvan A, Jagadeeswaran A, Subramanian N, Kumar SC, Mekala P. Formulation, optimization and evaluation of solid lipid nanoparticles for sustained oral delivery. Asian J Pharm Clin Res 2015;8:231-6.

35. Wissing S, Lippacher A, Müller R. Investigations on the occlusive properties of solid lipid nanoparticles (SLN). J Cosmet Sci 2001;52:313-24

36. Vijayan V, Aafreen S, Sakthivel S, Reddy KR. Formulation and characterization of solid lipid nanoparticles loaded Neem oil for topical treatment of acne. J Acute Dis 2013;2:282-6.

37. Zamarioli CM, Martins RM, Carvalho EC, Freitas LA. Nanoparticles containing curcuminoids (Curcuma longa): Development of topical delivery formulation. Rev Bras Farm 28;25:53-60.

38. Pandey R, Khuller GK. Solid lipid particle-based inhalable sustained drug delivery system against experimental tuberculosis. Tuberculosis (Edinb) 2005;85:227-34.

39. Xiong MH, Bao Y, Yang XZ, Zhu YH, Wang J. Delivery of antibiotics with polymeric particles. Adv Drug Deliv Rev 2014;78:63-76.

40. Imbuluzqueta E, Lemaire S, Gamazo C, Elizondo E, Ventosa N, Veciana J, et al. Cellular pharmacokinetics and intracellular activity against listeria monocytogenes and Staphylococcus aureus of chemically modified and nanoencapsulated gentamicin. J Antimicrob Chemother 2012;67:2158-64.

41. Briones E, Colino CI, Lanao JM. Delivery systems to increase the selectivity of antibiotics in phagocytic cells. J Control Rel 2008; 125:210-27.

42. Ahmad Z, Pandey R, Sharma S, Khuller GK. Alginate nanoparticles as antituberculosis drug carriers: Formulation development, pharmacokinetics and therapeutic potential. Indian J Chest Dis Allied Sci 2006;48:171-6

43. Mohammadi G, Valizadeh H, Barzegar-Jalali M, Lotfipour F, Adibkia K, Milani M. Development of azithromycin-PLGA nanoparticles, physiochemical characterization and antibacterial effect against Salmonella typhi. Colloids Surf B 2010;80:34-9.

44. Abeylath SC, Turos E, Dickey S, Lim DV. Glyconanobiotics: Novel carbohydrated nanoparticle antibiotics for MRSA and bacillus anthracis. Bioorg Med Chem 2008;16:2412-8.

45. Turos E, Shim JY, Wang Y, Greenhalgh K, Reddy GS, Dickey S, et al. Antibiotic-conjugated polyacrylate nanoparticles: New opportunities for development of anti-MRSA agents. Bioorg Med Chem Lett 2007; 17:53-6

46. Fattal E, Youssef M, Couvreur P, Andremont A. Treatment of experimental salmonellosis in mice with ampicillin-bound nanoparticles. Antimicrob Agents Chemother 1989;33:1540-3.

47. Jeong YI, Na HS, Seo DH, Kim DG, Lee HC, Jang MK, et al. Ciprofloxacin-encapsulated poly(DL-lactide-co-glycolide) nanoparticles and its antibacterial activity. Int J Pharm 2008;352:317-23.

48. Fresta M, Puglisi G, Giammona G, Cavallaro G, Micali N, Furneri PM. Pefloxacine mesilate-and ofloxacin-loaded polyethylcyanoacrylate nanoparticles: Characterization of $n$ the colloidal drug carrier formulation. J Pharm Sci 1995;84:895-902.

49. Misra R, Acharya S, Dilnawaz F, Sahoo SK. Sustained antibacterial activity of doxycycline-loaded poly (D, L-lactide-co-glycolide) and poly ( $\varepsilon$-caprolactone) nanoparticles. Nanomedicine 2009;4:519-30.

50. Espuelas MS, Legrand P, Loiseau PM, Bories C, Barratt G, Irache JM. In vitro antileishmanial activity of amphotericin $\mathrm{B}$ loaded in $\operatorname{poly}(\mathcal{E}$ caprolactone) nanospheres. J Drug Target 2002;10:593-9.

51. Dillen K, Vandervoort J, Van den Mooter G, Verheyden L, Ludwig A. Factorial design, physicochemical characterisation and activity of ciprofloxacin-PLGA nanoparticles. Int $\mathrm{J}$ Pharm 2004;275:171-87.

52. Dillen K, Vandervoort J, Van den Mooter G, Ludwig A. Evaluation of ciprofloxacin-loaded Eudragit@ RS100 or RL100/PLGA nanoparticles. Int J Pharm 2006;314:72-82.

53. Dillen K, Bridts C, Van der Veken P, Cos P, Vandervoort J, Augustyns $\mathrm{K}$, et al. Adhesion of PLGA or Eudragit ${ }^{\circledR} / \mathrm{PLGA}$ nanoparticles to Staphylococcus and Pseudomonas. Int J Pharm 2008;349:234-40.

54. Toti US, Guru BR, Hali M, McPharlin CM, Wykes SM, Panyam $\mathrm{J}$, et al. Targeted delivery of antibiotics to intracellular chlamydial infections using PLGA nanoparticles. Biomaterials 2011;32:6606-13.

55. Ungaro F, d'Angelo I, Coletta C, di Villa Bianca RD, Sorrentino R, Perfetto B, etal.Drypowders based on PLGAnanoparticles forpulmonary delivery of antibiotics: Modulation of encapsulation efficiency, release rate and lung deposition pattern by hydrophilic polymers. J Control Rel 2012;157:149-59.

56. Maya S, Indulekha S, Sukhithasri V, Smitha KT, Nair SV, Jayakumar R, et al. Efficacy of tetracycline encapsulated O-carboxymethyl chitosan nanoparticles against intracellular infections of Staphylococcus aureus. Int J Biol Macromol 2012;51:392-9.

57. Umamaheshwari RB, Jain NK. Receptor mediated targeting of lectin conjugated gliadin nanoparticles in the treatment of Helicobacter pylori. J Drug Target 2003;11:415-23.

58. Pichavant L, Bourget C, Durrieu MC, Héroguez V. Synthesis of pHsensitive particles for local delivery of an antibiotic via dispersion ROMP. Macromolecules 2011;44:7879-87.

59. Wróblewska M, Winnicka K. The effect of cationic polyamidoamine dendrimers on physicochemical characteristics of hydrogels with erythromycin. Int J Mol Sci 2015;16:20277-89.

60. Bhadra D, Yadav AK, Bhadra S, Jain NK. Glycodendrimeric nanoparticulate carriers of primaquine phosphate for liver targeting. Int J Pharm 2005;295:221-33.

61. Kim Y, Zeng F, Zimmerman SC. Peptide dendrimers from natural amino acids. Chem Eur J 1999;5:2133-8.

62. Tuuttila T, Lipsonen J, Lahtinen M, Huuskonen J, Rissanen K. Synthesis and characterization of chiral azobenzene dye functionalized Janus dendrimers. Tetrahedron 2008;64:10590-7.

63. Berger A, Gebbink RJ, van Koten G. Transition metal dendrimer catalysts. Dendrimer Catalysis. Berlin, Heidelberg: Springer; 2006. p. 1-38.

64. Sujitha V, Bhattacharya S, Prakasam K. Dendrimers and its application. Int Res J Pharm 2011;2:25-32.

65. Strydom SJ, Rose WE, Otto DP, Liebenberg W, de Villiers MM. Poly(amidoamine) dendrimer-mediated synthesis and stabilization of silver sulfonamide nanoparticles with increased antibacterial activity. Nanomedicine 2013;9:85-93. 
66. Winnicka K, Wroblewska M, Wieczorek P, Sacha PT, Tryniszewska EA. The effect of PAMAM dendrimers on the antibacterial activity of antibiotics with different water solubility. Molecules 2013;18:8607-17.

67. Mishra MK, Kotta K, Hali M, Wykes S, Gerard HC, Hudson AP, et al. PAMAM dendrimer-azithromycin conjugate nanodevices for the treatment of Chlamydia trachomatis infections. Nanomedicine 2011;7:935-44.

68. Cheng Y, Qu H, Ma M, Xu Z, Xu P, Fang Y, et al. Polyamidoamine (PAMAM) dendrimers as biocompatible carriers of quinolone antimicrobials: An in vitro study. Eur J Med Chem 2007;42:1032-8.

69. Nguyen PM, Zacharia NS, Verploegen E, Hammond PT. Extended release antibacterial layer-by-layer films incorporating linear-dendritic block copolymer micelles. Chem Mater 2007;19:5524-30.

70. Ma M, Cheng Y, Xu Z, Xu P, Qu H, Fang Y, et al. Evaluation of polyamidoamine (PAMAM) dendrimers as drug carriers of antibacterial drugs using sulfamethoxazole (SMZ) as a model drug. Eur J Med Chem 2007;42:93-8.

71. Bosnjakovic A, Mishra MK, Ren W, Kurtoglu YE, Shi T, Fan D, et al. Poly(amidoamine) dendrimer-erythromycin conjugates for drug delivery to macrophages involved in periprosthetic inflammation. Nanomedicine 2011;7:284-94.
72. Prasad BS, Gupta VR, Devanna N, Jayasurya K. Microspheres as drug delivery system-A review. J Global Trends Pharm Sci 2014;5:1961-72.

73. Kadam NR, Suvarna V. Microsphere: A brief review. Asian J Biomed Pharm Sci 2015;5:13-9.

74. Hejazi R, Amiji M. Stomach-specific anti-H. Pylori therapy. I: Preparation and characterization of tetracyline-loaded chitosan microspheres. Int J Pharm 2002;235:87-94.

75. Mallikarjun V, Sriharsha SN. Formulation and in vitro evaluation of Cefixime microspheres. Int J Pharm Bio Sci 2013;3:285-9.

76. Melake NA, Mahmoud HA, Al-Semary MT. Bactericidal activity of various antibiotics versus tetracycline-loaded chitosan microspheres against Pseudomonas aeruginosa biofilms. Afr J Microb Res 2012;6:5387-98

77. Hoppentocht M, Hagedoorn P, Frijlink HW, de Boer AH. Developments and strategies for inhaled antibiotic drugs in tuberculosis therapy: A critical evaluation. Eur J Pharm Biopharm 2014;86:23-30.

78. Brodt AM, Stovold E, Zhang L. Inhaled antibiotics for stable noncystic fibrosis bronchiectasis: A systematic review. Eur Respir J 2014;44:382-93.

79. Shaji J, Shaikh M. Drug-resistance tuberculosis: Recent approach in polymer based nanomedicine. Int J Pharm Pharm Sci 2016;8:1-6. 